chính xác và giá trị dự báo âm tính là $100 \%$. Kết quả của chúng tôi phù hợp với các nghiên cứu của Rockall và cs cũng như của Hricak và cs đều cho rằng đánh giá xâm lấn bàng quang, trực tràng $\mathrm{CHT}$ có giá trị dự báo âm tính $100 \%^{(3,5)}$. Sala và CS cho rằng $\mathrm{CHT}$ đánh giá xâm lấn bàng quang, trực tràng có độ chính xác $100 \%{ }^{(1)}$.

4.2.4. Giá trị của CHT trong đánh giá di căn hạch. Trong 47 trường hợp CHT phát hiện 3 trường hợp có hạch ở vùng tiểu khung kích thước > 10mm tăng tín hiệu trên Diffusion (b800-b1000) được chẩn đoán hạch di căn, kết quả GPB cho thấy chỉ có 2 trường hợp di căn hạch, 1 trường hợp còn lại là hạch viêm. Trong 44 trường hợp CHT không phát hiện được hạch di căn thì GPB xác nhận là đúng. Trong chẩn đoán hạch di căn CHT có độ đặc hiệu 97,8\%, độ chính xác $97,9 \%$, giá trị dự báo âm tính $100 \%$, độ nhạy là $2 / 2$ và giá trị dự báo dương tính là $2 / 3$.

Theo nghiên cứu của Sala và CS, phát hiện hạch di căn của CHT và CLVT đều có độ nhạy và độ đặc hiệu tương ứng là $43 \%$ và $73 \%{ }^{(1)}$. Nghiên cứu của Doãn Văn Ngọc, đánh giá hạch di căn CHT có độ nhạy không cao (7/18) nhưng độ chính xác khá cao $(88,9 \%)^{(4)}$

\section{KẾT LUÂ̂N}

Nghiên cứu 47 bệnh nhân UT CTC, nhận thấy giá trị rất cao của CHT trong đánh giá bilan xâm lấn vùng, gồm xâm lấn âm đạo, dây chằng rộng, trực tràng, bàng quang và hạch tiểu khung, với các giá trị chẩn đoán độ nhạy, độ đặc hiệu, giá trị dự báo âm tính và dương tính từ 95,7\% đến $100 \%$.

\section{TÀI LIẸU THAM KHẢO}

1. Sala E, Wakely S, Senior E, Lomas D. MRI of malignant neoplasms of the uterine corpus and cervix. AJR Am J Roentgenol. 2007;188(6):1577-1587.

2. Charis Bourgioti et al. MRI findings before and after abdominal radical trachelectomy (ART) for cervical cancer: a prospective study and review of the literature. Clin Radiol. 2014;69(7):678-686..

3. Rockall AG, Ghosh S, Alexander-Sefre F, et al. Can MRI rule out bladder and rectal invasion in cervical cancer to help select patients for limited EUA? Gynecol Oncol. 2006;101(2):244-249.

4. Doãn Văn Ngọc. Nghiên cứu đặc điểm hình ảnh và giá trị cộng hưởng từ 1.5 Tesla trong phân loại giai đoạn và theo dõi điêu trị ung thư cô tử cung, Trường Đại học Y Hà Nội; 2018.

5. Hricak H, Gatsonis C, Coakley FV, et al. Early invasive cervical cancer: CT and MR imaging in preoperative evaluation - ACRIN/GOG comparative study of diagnostic performance and interobserver variability. Radiology. 2007;245(2):491-498.

6. Sala E, Rockall AG, Freeman SJ, Mitchell DG, Reinhold C. The added role of MR imaging in treatment stratification of patients with gynecologic malignancies: what the radiologist needs to know. Radiology. 2013;266(3):717-740.

\title{
VAI TRÒ CỦA CHƯƠNG TRÌNH QUẢN LÝ SỬ DỤNG KHÁNG SINH TRONG ĐIỀU TRỊ VIÊM PHÚC MẠC TẠI MộT BỆNH VIỆN THÀNH PHỐ HỒ CHÍ MINH
}

\section{TÓM TẮT.}

Mục tiêu: Bước đâu đánh giá hiệu quả của chương trình quản lý sử dụng kháng sinh trên tính hợp lý của việc sử dụng thuốc trong điều trị viêm phúc mạc. Đối tượng-Phương pháp nghiên cứu: Nghiên cứu cắt ngang mô tả trên tất cả hồ sơ bệnh án của bệnh nhân được chẩn đoán viêm phúc mạc tại một bệnh viện hạng nhất Thành phố Hồ Chí Minh từ 10/2018-3/2019 (giai đoạn 1 , trước khi có chương trình quản lý sử dụng kháng sinh) và $10 / 2019-3 / 2020$ (giai đoạn 2, có áp

\footnotetext{
${ }^{1}$ Đại học Y Dược Thành phố Hồ Chí Minh Bềnh viện Chớ Rẫy

Chịu trách nhiệm chính: Võ Duy Thông

Email: duythong@ump.edu.vn

Ngày nhận bài: 25.12.2020

Ngày phản biện khoa học: 15.2.2021

Ngày duyệt băi: 26.2.2021
}

\section{Võ Duy Thông1,2, Trần Thiên Tân ${ }^{2}$}

dụng các biện pháp trong chương trình quản lý sử dụng kháng sinh). Sự hợp lý của kháng sinh được đánh giá dựa trên phác đồ của Bộ Y tế, SIS 2017. Đánh giá hiệu quả của chương trình bằng cách so sánh tỷ lệ sử dụng kháng sinh hợp lý và kết quả điều trị. Kết quả: Có 104 bệnh nhân (giai đoạn 1) và 107 bênh nhân (giai đoạn 2) được đưa vào nghiên cứu. Tuổi trung vị của mẫu nghiên cứu là 40-44 tuổi, nam giới chiếm 53,3-55,8\%. Các chủng vi khuẩn phân lập được nhiều nhất là $\mathrm{E}$. coli $(63,5 \%)$ và $K$. pneumoniae $(11,5 \%)$. Tỷ lệ sử dụng kháng sinh hợp lý ở giai đoạn 2 cao hơn có ý nghĩa thống kê so với giai đoan 1 theo khuyến cáo SIS 2017 $(43,9 \%$ so với $9,6 \%, p<0,001)$. Kết quả điều trị khỏi ở cả 2 giai đoạn đều là $99 \%$. Kết luân: Chương trình quản lý sử dụng kháng sinh tại bệnh viện giúp làm gia tăng tỷ lệ sử dụng kháng sinh hợp lý trong điều trị viêm phúc mạc.

Tư khoá: kháng sinh, viêm phúc mạc, chương trình quản lý sử dụng kháng sinh 


\section{SUMMARY \\ EFFECTIVENESS OF ANTIMICROBIAL STEWARSHIP PROGRAM ON TREATMENT OF PERITONITIS AT A HOSPITAL IN HOCHIMINH CITY}

Objective: To evaluate the role of antimicrobial stewardship program (ASP) in the appropriateness of anitibiotic use in treatment of peritonitis. Methods: A before and after cross-sectional study was conducted on medical records of patients diagnosed with peritonitis from $10 / 2018$ to $3 / 2019$ (before ASP) and from 10/2019 to 3/2020 (after ASP) at a hospital in Hochiminh City. Patient medical records were collected for data analysis including demographics, isolated organisms, antibiotic use, and treatment outcomes. The appropriateness of antibiotic use was assessed based on National antibiotic, SIS 2017. The effectiveness of ASP on treatment of cholecystitis was evaluated by comparing the rate of antibiotic appropriateness and treatment outcomes before and after applying ASP. Results: There were 104 medical records before ASP and 107 ones after ASP included in this study. The median age of patients was 40-44; $53.3-55.8 \%$ was man. E. coli $(63.5 \%)$ and $\mathrm{K}$. pneumoniae $(11.5 \%)$ were the most common isolated organisms. The rate of appropriate antibiotic use in empiric treatment increased from $9.6 \%$ to $43.9 \%$ ( $p=$ 0,04 ) based on SIS 2017 guideline. 99\% of patients recovered after treatment in both periods - before anf after ASP. Conclusion: The antimicrobial stewardship program increases the rate of appropriate antibiotic use in treatment of peritonitis.

Keywords: antibiotic use, peritonitis, antimicrobial stewardship program

\section{I. ĐĂTT VẤN ĐỀ}

Hiện nay đề kháng, đề kháng kháng sinh đang trở thành vấn đề nghiêm trọng, gây khó khăn trong việc điều trị, kéo dài thời gian nằm viện, tốn kém chi phí, tăng bệnh suất và tử suất. Theo một nghiên cứu năm 2012 tại 5 bệnh viện ở thành phố Hồ Chí Minh, các vi khuẩn gầy nhiễm khuẩn ổ bung có tỷ lệ tiết ESBL khá cao là Escherichia coli $(52,30 \%)$, Klebsiella spp. $(53,42 \%)$ và Proteus spp. (31,75\%) [1]. Viêm phúc mạc là tình trạng viêm của lá phúc mạc trong xoang bụng có mủ, giả mạc, dịch tiêu hóa, phân, dịch mật. Viêm phúc mạc thứ phát là bênh lý gặp thường xuyên do lan từ một ổ nhiễm trùng, võ áp xe, thủng tạng rỗng, đây là biến chứng nguy hiểm và có tỷ lệ tử vong cao nếu không điêu trị kịp thời [2]. Quản lý sử dụng kháng sinh trong điều trị các bệnh lý nhiễm khuẩn nói chung và các bệnh lý nhiễm khuẩn nặng nói riêng đang là nhiệm vụ quan trọng tại mỗi bênh viện. Nghiên cứu được tiến hành với mục tiêu bước đầu đánh giá vai trò của chương trình quản lý sử dụng kháng sinh trong điều trị viêm phúc mạc tại bệnh viện.

\section{II. ĐỐI TƯỢNG VÀ PHƯƠNG PHÁP NGHIÊN CỨU}

Tất cả hồ sơ bệnh án của bệnh nhân nhập viện điều trị nội trú, được chẩn đoán viêm phúc mac.

Phương pháp chọn mẫu. Nghiên cứu được chia làm 2 giai đoạn chính: Giai đoạn 1: từ tháng 10/2018 đến tháng 3/2019 (104 hồ sơ bệnh án); Giai đoạn 2: từ tháng 10/2019 đến tháng 3/2020 (107 hồ sơ bệnh án). Giữa 2 giai đoạn, từ tháng 9/2019, tại bệnh viện nghiên cứu bắt đầu triển khai chương trình quản lý sử dụng kháng sinh và ban hành hướng dần sử dung kháng sinh.

\section{Tiêu chuẩn chọn mấu:}

- Hồ sơ bệnh án của bệnh nhân có chẩn đoán viêm phúc mạc

- Tuổi đủ 18 trở lên.

- Điều trị nội trú tại khoa Tiêu hóa hoặc Gan mật tụy trong thời gian từ tháng 10/2018-3/2019 và tháng 10/2019-3/2020.

\section{Tiêu chuân loai trừ:}

- Bệnh nhân không đầy đủ thông tin hồ sơ bệnh án.

- Phu nữ mang thai.

- Bệnh nhân mắc HIV, bệnh lý hoặc dùng thuốc suy giảm miễn dịch.

Cỡ mẫu nghiên cứu. Tất cả hồ sơ bệnh án thỏa tiêu chuẩn chọn mẫu và không thuộ́c tiêu chuẩn loại trừ ở 2 giai đoan.

Thiết kế nghiên cứu. Nghiên cứu mô tả cắt ngang, so sánh trước - sau.

Đặc điểm mẫu nghiên cứu. Các thông tin bênh nhân: tuổi, giới tính, chức năng thân ban đầu, chẩn đoán, nguyên nhân gây bệnh, bệnh kèm, số bệnh kèm, triệu chứng lâm sàng, xét nghiệm cận lâm sàng (Bạch cầu (WBC), Neutrophil (NEU\%), CRP), can thiêp ngoại khoa (loại phẫu thuật, thời gian thực hiện).

Đặc điểm vi sinh và tình hình đề kháng kháng sinh. Chỉ định lấy mẫu bệnh phẩm, loại bệnh phẩm, kết quả cây mẫu bệnh phẩm, số chủng vi khuẩn phân lập được, đề kháng kháng sinh của từng vi khuẩn.

Khảo sát sử dụng kháng sinh và đánh giá tính hợp lý. Khảo sát kháng sinh được sử dụng, khảo sát kháng sinh điều trị theo kinh nghiệm (Phác đồ đơn trị/ phối hợp hai thuốc/ phối hợp ba thuốc)

Đánh giá hiệu quả của chương trình quản lý kháng sinh

So sánh kết quả giữa hai giai đoạn:

- Tỷ lê sử dụng kháng sinh hợp lý. Đánh giá tính hợp lý sử dụng kháng sinh (Bảng 1)

Bảng 1. Bảng tiêu chí đánh giá hợp lý sử dụng kháng sinh 


\begin{tabular}{|c|c|}
\hline $\begin{array}{l}\text { Tiêu chí } \\
\text { đánh giá }\end{array}$ & Cách đánh giá \\
\hline $\begin{array}{l}\text { Hợp } \\
\text { chỉ }\end{array}$ & $\begin{array}{l}\text { Đánh giá dựa trên các hướng dấn } \\
\text { điều trị: Hướng dẫn sử dụng } \\
\text { kháng sinh của Bộ Y tế Việt Nam } \\
\text { năm } 2015 \text { [3], SIS } 2017 \text { [4]. } \\
\text { Hợp lý lựa chọn kháng sinh khi } \\
\text { tuân thư } 1 \text { trong } 3 \text { hướng dẫn trên }\end{array}$ \\
\hline $\begin{array}{l}\text { Hợp lý về } \\
\text { liều }\end{array}$ & $\begin{array}{l}\text { Hợp lý khi tuân theo một trong } \\
\text { các hướng dẫn trên hoặc tờ } \\
\text { hướng dẫn sữ dụng thuốc }\end{array}$ \\
\hline $\begin{array}{l}\text { Hợp } \\
\text { chun }\end{array}$ & $\begin{array}{l}\text { Hợp lý: nếu có hợp lý cả về chỉ } \\
\text { định, liều dùng }\end{array}$ \\
\hline
\end{tabular}

Phân tích số liệu. Tất cả các phép kiểm thống kê được thực hiện với phần mềm thống kê $R$ và ngôn ngữ lập trình Python 2018, các kết quả được xem là có ý nghĩa thống kê khi $p<$ 0,05. Xác định tần số, tỷ lệ phần trăm, số trung bình: sử dụng phân tích thống kê mô tả. So sánh hai tỷ lệ: sử dụng phép kiểm chi bình phương. So sánh giá trị trung bình: t-test nếu phân phối chuẩn hoặc Mann-Whitney test nếu phân phối không chuẩn.

Vấn đề đạo đức: Đề tài đã được Hội đồng $Y$ đức Bệnh viện thông qua theo Giấy chấp thuận số 40/2020/BVTN-HĐYĐ ngày 16 tháng 03 năm 2019.

\section{KẾT QUẢ NGHIÊN CỨU}

3.1. Đặc điểm dịch tễ học của mẫu nghiên cứu. Đặc điểm của dân số nghiên cứu được trình bày trong bảng 2 .

Bảng 2. Đắc điểm của dân số nghiên cứu bệnh viêm phúc mạc

\begin{tabular}{|c|c|c|c|}
\hline Đặc điểm & $\begin{array}{c}\text { Giai } \\
\text { đoạn } 1 \\
(n=104)\end{array}$ & $\begin{array}{c}\text { Giai } \\
\text { đoạn } 2 \\
(n=107)\end{array}$ & $\begin{array}{r}\text { Giá } \\
\text { trị p }\end{array}$ \\
\hline Tuối & $44(31 ; 56)$ & $39(29 ; 54)$ & 0,48 \\
\hline$<65$ & $88(84,6 \%)$ & $96(89,7 \%)$ & \\
\hline$\geq 65$ & $16(15,4 \%)$ & $11(10,3 \%)$ & 0,36 \\
\hline \multicolumn{4}{|c|}{ Giới tính } \\
\hline Nam & $58(55,8 \%)$ & $57(53,3 \%)$ & \multirow{2}{*}{0,82} \\
\hline Nữ & $46(44,2 \%)$ & $50(46,7 \%)$ & \\
\hline $\begin{array}{l}\text { Chức năng } \\
\text { thận ban đâuu }\end{array}$ & $80 \pm 24$ & $79 \pm 22$ & 0,9 \\
\hline$\geq 60 \mathrm{~mL} /$ phút/ & $81(77,9 \%)$ & $86(80,4 \%)$ & \multirow{2}{*}{0,78} \\
\hline $\begin{array}{c}<60 \mathrm{~mL} / \text { phút/ } \\
1,73 \mathrm{~m}^{2}\end{array}$ & $23(22,1 \%)$ & $21(19,6 \%)$ & \\
\hline \multicolumn{4}{|c|}{ Nguyên nhân } \\
\hline Viêm ruột thừa & $75(72,1 \%)$ & $79(73,8 \%)$ & \multirow[b]{2}{*}{0,9} \\
\hline Thủng tạng rống & $21(20,2 \%)$ & $19(17,8 \%)$ & \\
\hline
\end{tabular}

\begin{tabular}{|c|c|c|c|}
\hline Khác & $8(7,7 \%)$ & $98,4 \%)$ & \\
\hline \multicolumn{4}{|c|}{ Số bệnh kèm } \\
\hline 0 & $61(58,7 \%)$ & $68(63,5 \%)$ & \\
\hline 1 & $35(33,6 \%)$ & $25(23,4 \%)$ & 0,3 \\
\hline 2 & $5(4,8 \%)$ & $9(8,4 \%)$ & \\
\hline$\geq 3$ & $3(2,9 \%)$ & $5(4,7 \%)$ & \\
\hline \multicolumn{4}{|c|}{ Bệnh mắc kèm } \\
\hline Bệnh tim mạch & $17(16,3 \%)$ & $15(14 \%)$ & 0,78 \\
\hline Đái tháo đường & $11(10,6 \%)$ & $11(10,3 \%)$ & 1 \\
\hline Viêm dạ dày & $15(14,4 \%)$ & $9(8,4 \%)$ & 0,63 \\
\hline Khác & $7(6,7 \%)$ & $13(12,1 \%)$ & 0,27 \\
\hline \multicolumn{4}{|c|}{ Triệu chứng lâm sàng } \\
\hline Dấu Murphy & $1(1 \%)$ & $0(0 \%)$ & 0,99 \\
\hline Đề kháng & $92(88,5 \%)$ & $86(80,6 \%)$ & 0,15 \\
\hline $\begin{array}{c}\text { Đau hạ sườn } \\
\text { phải }\end{array}$ & $0(0 \%)$ & $1(0,93 \%)$ & 1 \\
\hline $\begin{array}{c}\text { Đau hố chậu } \\
\text { phải }\end{array}$ & $66(63,5 \%)$ & $63(58,9 \%)$ & 0,59 \\
\hline \multicolumn{4}{|c|}{ Xét nghiệm cận lâm sàng bất thường } \\
\hline WBC & $86(82,7 \%)$ & $89(83,2 \%)$ & 1 \\
\hline NEU\% & $92(88,5 \%)$ & $92(87,9 \%)$ & 0,74 \\
\hline $\begin{array}{c}\mathrm{CRP}\left(\mathrm{n}_{1}=90\right. \\
\left.\mathrm{n}_{2}=95\right)\end{array}$ & $71(78,9 \%)$ & $70(73,7 \%)$ & 0,51 \\
\hline \multicolumn{4}{|c|}{ Can thiệp ngoại khoa } \\
\hline \begin{tabular}{|c|} 
Được can thiệp \\
ngoai khoa
\end{tabular} & 10 & $107(100 \%)$ & 1 \\
\hline Phầu thuât & $104(100 \%)$ & $107(100 \%)$ & \multirow{3}{*}{1} \\
\hline Thủ thuật & $0(0 \%)$ & $0(0 \%)$ & \\
\hline $\begin{array}{l}\text { Thủ thuât + } \\
\text { phẫu thuật }\end{array}$ & $0(0 \%)$ & $0(0 \%)$ & \\
\hline \multicolumn{4}{|c|}{ Loại phâu thuật } \\
\hline $\begin{array}{c}\text { Nội soi }\left(\mathrm{n}_{1}=\right. \\
104, \\
\left.\mathrm{n}_{2}=107\right)\end{array}$ & $\begin{array}{c}94 \\
(90,4 \%)\end{array}$ & $102(95,3 \%)$ & \multirow{2}{*}{0,26} \\
\hline $\begin{array}{c}\text { Mố mơ }\left(n_{1}=\right. \\
\left.104, n_{2}=107\right)\end{array}$ & $\begin{array}{c}10 \\
(9,6 \%)\end{array}$ & $\begin{array}{c}5 \\
(4,7 \%)\end{array}$ & \\
\hline $\begin{array}{c}\text { Thời gian phất } \\
\text { thuật (phút) }\end{array}$ & $77 \pm 36$ & 76 & 0,79 \\
\hline
\end{tabular}

3.2. Đặc điểm vi sinh của mấu nghiên cứu

Tỷ lệ bệnh nhân có chỉ định cấy mấu bệnh phẩm ở 2 giai đoạn lần lượt là $26,9 \%$ và $34,6 \%$. Kết quả cây mẫu dương tính là > $65 \%$ (Bảng 3 ).

Bảng 3. Đặc điểm vi sinh bệnh nhân viêm phúc mạc

\begin{tabular}{|c|c|c|c|}
\hline Đặc điểm & $\begin{array}{c}\text { Giai đoạn } 1 \\
(n=104)\end{array}$ & \begin{tabular}{|c|} 
Giai đoạn 2 \\
(n = 107)
\end{tabular} & $\begin{array}{c}\text { Giá trị } \\
\text { p }\end{array}$ \\
\hline \multicolumn{4}{|c|}{ Chỉ định lấy mấu bệnh phấm } \\
\hline Có & $28(26,9 \%)$ & $37(34,6 \%)$ & \multirow[b]{2}{*}{0,29} \\
\hline Không & $76(73,1 \%)$ & $70(65,4 \%)$ & \\
\hline \multicolumn{3}{|c|}{ Loại bệnh phẩm } & \\
\hline Máu & $2(1,9 \%)$ & $1(0,9 \%)$ & \multirow{2}{*}{0,433} \\
\hline Áp xe & $13(12,5 \%)$ & $13(12,1 \%)$ & \\
\hline
\end{tabular}


\begin{tabular}{|l|l|l|}
\hline Dịch ố bụng $13(12,5 \%)$ & $22(20,6 \%)$ \\
\hline
\end{tabular}

Kết quả cấy mầu bệnh phẩm

$\left(\mathbf{n}_{1}=\mathbf{2 8}, \mathbf{n}_{\mathbf{2}}=\mathbf{3 7}\right)$

\begin{tabular}{|c|c|c|c|}
\hline Dương tính & $19(67,9 \%)$ & $27(73 \%)$ & \multirow{2}{*}{0,86} \\
\cline { 1 - 2 } Âm tính & $9(32,1 \%)$ & $10(27 \%)$ & 0,86 \\
\cline { 1 - 2 }
\end{tabular}

Số chủng phân lập được từ mấu cây $\left(\mathbf{n}_{1}=\mathbf{2 8}, \mathbf{n}_{2}=\mathbf{3 7}\right)$

\begin{tabular}{|c|c|c|c|}
\hline 0 & $9(32,2 \%)$ & $10(27 \%)$ & \\
\hline 1 & $16(57,1 \%)$ & $24(64,9 \%)$ & 0,81 \\
2 & $3(10,7 \%)$ & $3(8,1 \%)$ & 0,8 \\
\hline
\end{tabular}

Các tác nhân gây bệnh thường gặp nhất là Escherichia coli $(63,5 \%)$ và Klebsiella pneumoniae
$(11,5 \%)$. Các vi khuẩn gram dương có tỷ lệ là 9,6\% trên các mẫu cấy dương tính (Bảng 4)

Bảng 4. Tác nhân gây bệnh thường gặp ở bệnh nhân viêm phúc mạc

\begin{tabular}{|c|c|c|}
\hline Tên vi khuẩn & $\begin{array}{c}\text { Tần } \\
\text { suất }\end{array}$ & $\begin{array}{c}\text { Tỷ lệ } \\
\text { (n = 52) }\end{array}$ \\
\hline Escherichia coli & 33 & $63,5 \%$ \\
\hline Klebsiella pneumoniae & 6 & $11,5 \%$ \\
\hline Pseudomonas aeruginosa & 4 & $7,7 \%$ \\
\hline Enterobacter aerogenes & 1 & $1,9 \%$ \\
\hline Acinetobacter baumannii & 2 & $3,9 \%$ \\
\hline Acinetobacter junii & 1 & $1,9 \%$ \\
\hline Enterococcus faecalis & 5 & $9,6 \%$ \\
\hline
\end{tabular}

Bảng 5. Thống kê tỷ lệ nhạy cảm tích lưy 2 giai đoạn với kháng sinh của vi khuẩn phân lập trên bệnh nhân viêm phúc mạc

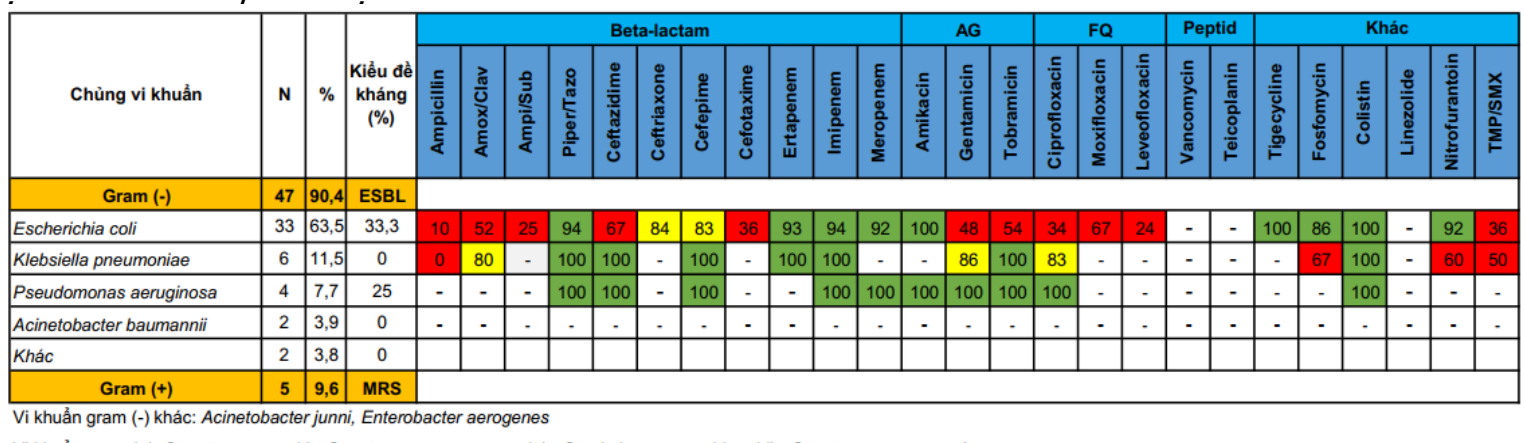

Vi khuẩn gram (+): Streptococcus mitis, Streptococcus parasanguinis, Staphylococcus epidermidis, Streptococcus group A

3.3.Sử dụng kháng sinh trong điêu trị viêm phúc mạc. Kết quả cho thãy cho thây giảm việc sử dụng phối hợp 2 thuốc và tăng đơn trị khi bắt đầu điều trị $(p=0,01)$. Tỷ lệ sử dụng moxifloxacin phối hợp metronidazol, ertapenem phối hợp với metronidazol giảm đáng kể và tăng tỷ lệ sử dụng các thuốc đơn trị. Tỷ lệ ceftriaxon phối hợp metronidazol để khởi đâu điều trị cũng tăng lên đáng kể.

Bảng 6. Phác đồ kháng sinh sử dụng theo kinh nghiệm ban đầu

\begin{tabular}{|c|c|c|c|c|}
\hline Kháng sinh 1 & Kháng sinh 2 & Kháng sinh 3 & $\begin{array}{c}\text { Tần suất } \\
\left(\mathrm{n}_{1}=104\right)\end{array}$ & $\begin{array}{c}\text { Tân suất } \\
\left(\mathrm{n}_{2}=107\right)\end{array}$ \\
\hline Đơn trị & & & $15(14,4 \%)$ & $32(29,9 \%)$ \\
\hline Cefoxitin & - & - & 1 & 6 \\
\hline Moxifloxacin & - & - & 12 & 15 \\
\hline Ertapenem & - & - & 1 & 5 \\
\hline Imipenem/cilastatin & - & - & 1 & 3 \\
\hline Khác ${ }^{a}$ & - & - & 0 & 3 \\
\hline Phối hợp hai & & & $77(74 \%)$ & $67(62,6 \%)$ \\
\hline \multirow{3}{*}{ Moxifloxacin } & Metronidazol & - & 42 & 20 \\
\hline & Amikacin & & 0 & 3 \\
\hline & Gentamicin & & 0 & 2 \\
\hline \multirow{3}{*}{ Cefoxitin } & Metronidazol & - & 6 & 3 \\
\hline & Levofloxacin & - & 1 & 0 \\
\hline & Gentamicin & - & 1 & 1 \\
\hline Ertapenem & Metronidazol & - & 17 & 5 \\
\hline Cefoperazon/sulbactam & Metronidazol & - & 8 & 5 \\
\hline \multirow{2}{*}{ Imipenem/cilastatin } & Metronidazol & - & 1 & 2 \\
\hline & Moxifloxacin & - & 1 & 2 \\
\hline \multirow[b]{2}{*}{ Ceftriaxon } & Metronidazol & - & 0 & 14 \\
\hline & Amikacin & - & 0 & 1 \\
\hline
\end{tabular}


TẠP CHÍ Y HỌC VIẸT NAM TẬP 500 - THÁNG 3 - SÓ 1 - 2021

\begin{tabular}{|c|c|c|c|c|}
\hline & Gentamicin & - & 0 & 1 \\
\hline Ciprofloxacin & Metronidazol & - & 0 & 6 \\
\hline Khác ${ }^{b}$ & & & 1 & 2 \\
\hline Phối hợp ba & & & $12(11,5 \%)$ & $8(7,5 \%)$ \\
\hline \multirow{6}{*}{ Moxifloxacin } & \multirow{6}{*}{ Metronidazol } & Amikacin & 3 & 0 \\
\hline & & Cefepim & 1 & 0 \\
\hline & & $\begin{array}{l}\text { Cefoperazon/ } \\
\text { sulbactam }\end{array}$ & 1 & 0 \\
\hline & & Ertapenem & 1 & 0 \\
\hline & & Netilmicin & 1 & 0 \\
\hline & & Gentamicin & 0 & 1 \\
\hline \multirow{2}{*}{ Cefoperazon/sulbactam } & \multirow{2}{*}{ Metronidazol } & Amikacin & 1 & 0 \\
\hline & & Gentamicin & 1 & 0 \\
\hline \multirow{3}{*}{ Imipenem/cilastatin } & \multirow{3}{*}{ Metronidazol } & Gentamicin & 0 & 1 \\
\hline & & Levofloxacin & 0 & 2 \\
\hline & & Moxifloxacin & 0 & 2 \\
\hline Cefoxitin & Metronidazol & Gentamicin & 1 & 1 \\
\hline Khác ${ }^{c}$ & Khác ${ }^{c}$ & Khác ${ }^{c}$ & 2 & 2 \\
\hline \multicolumn{5}{|c|}{$\begin{array}{l}\text { Khác }{ }^{\mathrm{a}} \text { : piperacillin/tazobactam, amoxicillin/clavulanate, ampicillin/sulbactam, cefpirom, ceftriaxon } \\
\text { Khác }{ }^{\mathrm{b}} \text { piperacillin/tazobactam }+ \text { amikacin, piperacillin/tazobactam }+ \text { levofloxacin, cefuroxim }+ \\
\text { metronidazol, cefpirom }+ \text { metronidazol, clindamycin }+ \text { metronidazol, meropenem + metronidazol, } \\
\text { gentamicin + metronidazol, cefepim + metronidazol }\end{array}$} \\
\hline
\end{tabular}

3.4. Hiệu quả của chương trình quản lý sử dụng kháng sinh

Tính hợp lý của kháng sinh. Tất cả các bệnh nhân trong nghiên cứu đều được khởi đầu điều trị bằng kháng sinh kinh nghiệm. Tính hợp lý sử dụng kháng sinh kinh nghiệm dựa theo các khuyến cáo tham khảo được trình bày trong Bảng 6.

Bảng 7. Tỷ lệ sử dụng hợp lý kháng sinh kinh nghiệm theo các khuyến cáo

\begin{tabular}{|c|c|c|c|c|c|}
\hline Tính hợp lý & \multicolumn{2}{|c|}{ Giai đoạn 1 $(\mathbf{n}=\mathbf{1 0 4})$} & \multicolumn{2}{|c|}{ Giai đoạn 2 (n= 107) } & Giá trị p \\
\hline Hợp lý chỉ đinh & $67(\mathrm{n}=104)$ & $64,4 \%$ & $75(\mathrm{n}=107)$ & $70,1 \%$ & 0,46 \\
\hline Hợp lý liều dùng & $65(\mathrm{n}=67)$ & $97 \%$ & $73(\mathrm{n}=75)$ & $97,3 \%$ & 1 \\
\hline Hợp lý chung & $65(\mathrm{n}=104)$ & $62,5 \%$ & $73(\mathrm{n}=107)$ & $68,2 \%$ & 0,47 \\
\hline
\end{tabular}

Do các khuyến cáo quốc tế có một số điểm đồng thuận và không tương đồng với khuyến cáo Bộ Y tế, nhất là việc sử dụng phác đồ ky khí kép được đề cập trong phác đô của Bộ Y tế 2015 nhưng không có trong các khuyến cáo quốc tế. Chúng tôi phân tích thêm sự hợp lý của loại kháng sinh theo khuyến cáo quốc tế. Tỷ lệ sử dụng hợp lý kháng sinh kinh nghiệm theo khuyến cáo quốc tế (SIS 2017) được trình bày trong bảng 8 .

Bảng 8. Tỷ lệ sử dụng hợp lý kháng sinh kinh nghiệm theo SIS 2017

\begin{tabular}{|c|c|c|c|c|c|}
\hline Tính hợp lý & \multicolumn{2}{|c|}{ Giai đoạn 1 (n= 104) } & \multicolumn{2}{c|}{ Giai đoạn 2 (n= 107) } & Giá trị p \\
\hline Hợp lý chì đinh & $12(n=104)$ & $11,5 \%$ & $49(n=107)$ & $45,8 \%$ & $<\mathbf{0 , 0 0 1}$ \\
\hline Hợp lý liều dùng & $10(n=12)$ & $83,3 \%$ & $47(n=49)$ & $95,9 \%$ & 0,35 \\
\hline Hợp lý chung & $10(n=104)$ & $9,6 \%$ & $47(n=107)$ & $43,9 \%$ & $<\mathbf{0 , 0 0 1}$ \\
\hline
\end{tabular}

Kết quả điêu trị

Bảng 9. Kết quả điều trị một số bệnh lý viêm phúc mac

\begin{tabular}{|c|c|c|c|}
\hline $\begin{array}{c}\text { Kết quả điêuu } \\
\text { trị }\end{array}$ & $\begin{array}{c}\text { Giai đoạn 1 } \\
(\mathbf{n = 1 0 4})\end{array}$ & $\begin{array}{c}\text { Giai đoạn 2 } \\
(\mathbf{n}=\mathbf{1 0 7})\end{array}$ & $\begin{array}{c}\text { Giá } \\
\text { trị p }\end{array}$ \\
\hline $\begin{array}{c}\text { Điều trị thành } \\
\text { công }\end{array}$ & $103(99 \%)$ & $106(99,1 \%)$ & 1 \\
\hline Khỏi & 55 & $61(57 \%)$ & \multirow{2}{*}{0,64} \\
\hline Đõ̃ giảm & 48 & $45(42,1 \%)$ & \\
\hline
\end{tabular}

\begin{tabular}{|c|c|c|c|}
\hline $\begin{array}{c}\text { Diều trị thất } \\
\text { bại }\end{array}$ & $1(1 \%)$ & $1(0,9 \%)$ & 1 \\
\hline $\begin{array}{c}\text { Không thay } \\
\text { đổi }\end{array}$ & $0(0 \%)$ & $0(0 \%)$ & \\
\hline $\begin{array}{c}\text { Nă̆ng hơn } \\
\text { (xin về) }\end{array}$ & $1(1 \%)$ & $1(0,9 \%)$ & 1 \\
\hline Tứ vong & $0(0 \%)$ & $0(0 \%)$ & \\
\hline
\end{tabular}

\section{BÀN LUẬN}

Theo khuyễn cáo IDSA 2010, các bệnh nhân 
nhiễm khuẩn ổ bung ở mức độ nhe không cần thiết phải lấy mẫu bệnh phẩm [5]. Do đó, tỷ lệ cấy vi sinh là tương đối thấp và phần lớn mẫu bênh phẩm được lấy từ ổ khởi phát. Tỷ lệ cấy vi sinh đối với các bệnh tăng từ $26,9 \%$ lên $34,6 \%$, tỷ lệ cấy mẫu dương tính cũng tăng $67,9 \%$ lên $73 \%$ ở hai giai đoạn. Tỷ lệ mẩu cấy dương tính trong nghiên cứu của chúng tôi khá tương đồng so với nghiên cứu CIAOW (2014) là 62,7\% [6].

Trong các mẫu cây dương tính, các vi khuẩn gram âm chiếm đa số (75\%) khá tương đồng với nghiên cứu CIAOW (2014) với tỷ lệ cấy vi khuẩn gram âm là $71,9 \%$ [6]. Trong nghiên cứu của Montravers P. và cộng sự (2009) thực hiện trên 540 mẫu vi sinh có kêt quả với vi khuẩn gram âm chiếm 69\%[7]. Trong các vi khuẩn gram âm, Escherichia coli và Klebsiella pneumoniae là 2 vi khuẩn thường gặp nhất với tỷ lệ lần lượt là $64,9 \%$ và $18,9 \%$. So sánh với nghiên cứu của Trần Thị Thanh Nga và cộng sự (2014) [8] với Escherichia coli $73 \%$ (2010) và Klebsiella pneumoniae $16 \%$ (2010). Đây cũng là 2 vi khuẩn phổ biến nhất trong các bệnh lý NTÔB $[5,7]$.

Chúng tôi ghi nhận tỷ lệ vi khuẩn Escherichia coli tiết ESBL là $33 \%$ và Klebsiella pneumoniae không phát hiện ra chủng tiết ESBL, tuy nhiên do mẫu cấy dương tính khá ít nên kết quả này có thể chưa phản ánh đúng thực trạng vi khuẩn đề kháng tại bệnh viện. Trong nghiên cứu SMART [9] tỷ lê tiết ESBL của Escherichia coli là $18 \%$ và Klebsiella pneumoniae là $26 \%$, trong nghiên cứu CIAOW (2014) [6] tỷ lệ tiết ESBL là $14,8 \%$ và $23,4 \%$ với 2 vi khuẩn trên. Tuy nhiên, tỷ lệ tiết ESBL trong nghiên cứu của chúng tôi thấp hởn so với nghiên cứu của Trần Thị Thanh Nga và cộng sự [8] khi ghi nhận tỷ lệ tiết ESBL là khá cao $60 \%$ với Escherichia coli và $50 \%$ với Klebsiella pneumoniae. Điều này có thể do nghiên cứu của Trân Thị Thanh Nga khảo sát trên mẫu vi sinh trong 3 năm, do đó có số lượng mẫu nhiêu và tỷ lệ của các mẫu bệnh nhân nhiểm khuẩn ổ bụng do chăm sóc y tế cao nên tỷ lệ vi khuẩn tiết ESBL cao hơn nghiên cứu của chúng tôi.

So sánh 2 giai đoạn trước và sau khi triển khai chương trình quản lý sử dụng kháng sinh tại bệnh viện, tỷ lệ hợp lý chung tăng từ $62,5 \%$ lên $68,2 \%$ sự khác biệt không có ý nghĩa thống kê $(\mathrm{p}=0,47)$. Tuy nhiên, khi xét chỉ dựa trên khuyến cáo quốc tế, tính hợp lý tăng từ $9,6 \%$ tăng lên $43,9 \%(p<0,001)$. Đây là kết quả từ việc giảm sử dụng moxifloxacin phối hợp với metronidazol, thay vào đó là tăng sử dụng moxifloxacin đơn trị hoặc sử dụng ceftriaxon phối hợp với metronidazol. Việc giảm sử dụng phác đồ ky khí kép ở bệnh nhân viêm phúc mạc có vai trò của của chương trình quản lý sử dụng kháng sinh khi thường xuyên khuyến cáo các bác sĩ cân nhắc thay đổi lựa chọn kháng sinh điều trị.

Tỷ lệ điêu trị thành công trong nghiên cứu là $99 \%$ và $99,1 \%$ ở 2 giai đoạn, chỉ có 1 bệnh nhân nặng hơn và xin về ở mối giai đoạn mà chúng tôi quan sát được, so sánh với nghiên cứu của Kulwicki B. và cộng sự (2017) với tỷ lệ thành công ở 2 giai đoạn là $95,7 \%$ và $98,5 \%$. Các bệnh lý nhiễm trùng ổ bụng như viêm phúc mạc là bệnh lý cấp tính, do đó nếu được phát hiên sớm và có các biên pháp kiểm soát nguồn bênh, dẫn lưu và phẫu thuật sẽ cho tỷ lệ thành công cao $[6,7]$.

\section{KẾT LUÂN}

Việc xác định được chủng vi khuẩn gây bệnh, đề kháng kháng sinh giúp ích trong lựa chọn kháng sinh hợp lý để điều trị. Chương trình quản lý sử dụng kháng sinh tại bệnh viện là chương trình thiết thực giúp làm tắng tỷ lệ sử dụng kháng sinh hợp lý trong điều trị viêm phúc mạc tại bệnh viện.

\section{TÀI LIÊU THAM KHẢO}

1. Nquyễn Thanh Bảo, Cao Minh Nqa, Trân Thi Thanh Nqa và cônq sứ (2012), "Chon lưa khánq sinh ban đầu trong điều tri nhiễm khuẩn bênh viên tai môt số bênh viên TP. Hồ Chí Minh", Tap chí Y Hoc TP Hồ Chí Minh, 16(1), 206 - 214.

2. Mazuski JE., Tessier JM., Mav AK., et al. (2017), "The suraical infection societv revised quidelines on the manaqement of intra-abdominal infection", Surg Infect, 18 (1), 1 - 76

3. Bộ Y tế (2015), Hướng dân sử dụng kháng sinh, $159-192,316-322$.

4. Mazuski JE., Tessier JM., Mav AK., et al. (2017), "The suraical infection society revised quidelines on the manaqement of intra-abdominal infection", Surg Infect, 18 (1), 1 - 76.

5. Solomkin JS., Mazuski JE., Bradley JS., et al. (2010), "Diagnosis and management of complicated intra-abdominal infection in adults and children: Guidelines by the Surgical Infection Society and the Infectious Diseases Society of America". Clin Infect Dis: 50, 133 - 164.

6. Massimo S., Catena F., Ansaloni L., et al. (2014), "Complicated intra-abdominal infections worldwide: The definitive data of the CIAOW Study". World J Emera Surq, 9, 37.

7. Montravers P., Lepape A., Dubreuil L., et al. (2009) "Clinical and microbioloaical profiles of communitv-acauired and nosocomial intraabdominal infections: Results of the French prospective, observational EBIIA study", ] Antimicrob Chemother, 63, $785-794$.

8. Trân Thi Thanh Nqa, Nquvễn Tấn Cườnq, Pham Hữu Thiên Chí, Đoàn Tiến Mṽ (2014), "Nhiễm khuẩn ổ buna - các vi khuẩn thườna qăp và khuynh hướna đề khána khána sinh", Tạp chí Y Học TP. Hồ Chí Minh. 18 (2), 491-494. 